\title{
Warming mediates intraspecific multiple predator effects from an invasive crustacean
}

\author{
Ross N. Cuthbert ${ }^{1} \cdot$ Ryan J. Wasserman ${ }^{2} \cdot$ Tatenda Dalu $^{3} \cdot$ Elizabeta Briski $^{1}$
}

Received: 9 October 2020 / Accepted: 25 January 2021 / Published online: 17 February 2021

(c) The Author(s) 2021

\begin{abstract}
Invasive alien species impacts might be mediated by environmental factors such as climatic warming. For invasive predators, multiple predator interactions could also exacerbate or dampen ecological impacts. These effects may be especially pronounced in highly diverse coastal ecosystems that are prone to profound and rapid regime shifts. We examine emergent effects of warming on the strength of intraspecific multiple predator effects from a highly successful invasive gammarid Gammarus tigrinus, using a functional response approach towards larval chironomids (feeding rates under different prey densities). Single predator maximum feeding rates were three-times higher at $24{ }^{\circ} \mathrm{C}$ compared to $18{ }^{\circ} \mathrm{C}$ overall, with potentially prey destabilising type II functional responses exhibited. However, pairs of gammarids exhibited intraspecific multiple predator effects that were in turn mediated by temperature regime, whereby synergisms were found at the lower temperature (i.e. positive non-trophic interactions) and antagonisms detected at the higher temperature (i.e. negative non-trophic interactions) under high prey densities. Accordingly, warming scenarios may worsen the impact of this invasive alien species, yet implications of temperature change are dependent on predator-predator interactions. Emergent effects between abiotic and biotic factors should be considered in ecological impact predictions across habitat types for invasive alien species.
\end{abstract}

\section{Introduction}

Biological invasions are a major driver of global biodiversity loss through ecological impacts that disrupt the functioning of natural systems (Vilà et al. 2011; Simberloff et al. 2013; Dick et al. 2017). Whilst key drivers of change, the success and impacts of invasive alien species can be mediated by other human-induced alterations, such as habitat and climate changes (Didham et al. 2005; Pyšek et al. 2020). Accordingly, context-dependencies present a major challenge to ecological impact prediction (Ricciardi et al. 2013), with

Responsible Editor: F. Bulleri.

Reviewed by undisclosed experts.

Ross N. Cuthbert

rossnoelcuthbert@gmail.com

1 GEOMAR Helmholtz-Zentrum für Ozeanforschung Kiel, 24105 Kiel, Germany

2 Department of Zoology and Entomology, Rhodes University, Makhanda 6140, South Africa

3 School of Biology and Environmental Sciences, University of Mpumalanga, Nelspruit 1200, South Africa myriad abiotic and biotic factors heightening and dampening invader impacts via emergent effects (Dickey et al. 2020). This is particularly the case in nearshore aquatic ecosystems, where temperature regime shifts can decouple keystone trophic interactions in favour of invasive consumers (Morón Lugo et al. 2020). In highly productive coastal waters in particular, changes to temperature, salinity, $\mathrm{pH}$, dissolved oxygen and eutrophication can occur rapidly, potentially disrupting ecosystem structure and function (Boyd et al. 2018). These systems are also especially prone to invasion, with increasing intensity of globalised trade and transport networks connecting discrete coastal habitats and their species communities (Casties et al. 2016).

Invasive predators can be particularly damaging to the stability of native assemblages through an array of trophic (i.e., density-mediated) and non-trophic (i.e., trait-mediated) interactions (Platvoet et al. 2009; Anton et al. 2020). Advances have recently paralleled quantifications of invasive species functional responses with the magnitude of their infield ecological impact (Dick et al. 2014). The functional response approach quantifies resource use of a consumer as a function of resource density, allowing for comparative elucidation of density-dependences in ecological impacts under a range of abiotic variables (e.g., warming; Wasserman et al. 
2018) and species compositions (e.g., presence of multiple predators; Sentis and Boukal 2018). Classically, the functional response has been characterised discretely into three forms: types I (linear), II (hyperbolic) and III (sigmoidal), whereby type II feeding relationships can impart greatest impact due to high feeding rates at low resource (e.g. prey) densities (Holling 1959; Hassell 1978). However, impact predictions for invasive alien species have often been grounded in comparisons of single predators, which ignore emergent multiple predator effects (Sih et al. 1998; Médoc et al. 2013), with predators rarely present singularly in natural communities. For invaders, predator-predator interactions might thus profoundly mediate their impacts through emergent antagonisms and synergisms that can dampen or exacerbate ecological impacts, respectively (Wasserman et al. 2016). In turn, the strengths of multiple predator interactions might be further altered by temperature regime and prey density (Sentis et al. 2017), given the primacies of temperature and prey availability in foraging behaviour (Englund et al. 2011), necessitating quantitative investigations into emergent effects among these parameters.

The present study thus quantifies the influence of warming and predator density on the functional response of a widespread invasive predator that has invaded marine, brackish and freshwater environments in recent decades i.e. Gammarus tigrinus (Crustacea: Amphipoda) Sexton, 1939. Native to North America, this thermophilous and euryhaline species has invaded many European aquatic ecosystems (Casties et al. 2016; Paiva et al. 2018). Indeed, this species is one of few invasive gammarids that has successfully transitioned between marine and freshwater environments (Cuthbert et al. 2020), and is widely distributed and spreading in the brackish waters of the Baltic Sea (Rewicz et al. 2019). Gammarus tigrinus is known to actively feed on a range of aquatic invertebrates and prioritises carnivory to maximise energy intake, irrespective of temperature (Pellan et al. 2016). For this experiment, we used larval chironomid prey. These sediment-dwelling, free-swimming prey occupy benthic areas of waterbodies, and are a widespread and diverse group in the Baltic Sea-estimated to comprise approximately $30 \%$ of the macrozoobenthos species in the system, with as many as 230 species there (Ojaveer et al. 2010). Given that temperature regime is closely aligned with feeding rates (Englund et al. 2011), and gammarids within the same guild are known to interact (Platvoet et al. 2009), we expected (1) warming to increase gammarid functional responses towards live prey, and (2) intraspecific multiple predator effects to mediate ecological impacts of invasive gammarids differentially between temperatures, given increasing foraging intensities with warming that exacerbate predator-predator interactions.

\section{Materials and methods}

\section{Animal collection and experimental design}

The predators, G. tigrinus, were obtained from Travemünde, Lübeck, Germany $\left(53^{\circ} 83^{\prime} \mathrm{N} 10^{\circ} 64^{\prime} \mathrm{E}\right)$ during summer 2017 and transported to a controlled environment chamber $\left(18{ }^{\circ} \mathrm{C} ; 12: 12\right.$ light and dark regime) at GEOMAR Helmholtz Centre for Ocean Research Kiel, Germany in source water. The salinity at the time of sampling Travemünde was $10 \mathrm{ppt}$, owing to adjacent freshwater inputs from an inland waterway that reduce the salinity of the site. A kick-net was used to collect gammarids from within macroalgae at nearshore parts of the site. In the chamber, gammarids were housed in $56 \mathrm{~L}$ aquaria $(\sim 100$ individuals per aquaria), after identification, containing filtered Baltic Sea water from Kiel Fjord that was mixed with tap water to reach the desired ambient salinity of the collected population (10 ppt). Water from the Kiel Fjord was used for practical purposes over the acclimation period, however, laboratory conditions were calibrated to reflect those of the sampling location as much as possible. In the aquaria, water was continually pumped through a filtration system in each tank, and each tank contained a mixture of artificial floating vegetation and stones to provide habitat structure. Gammarids were housed in laboratory conditions and acclimated for multiple generations ( $>1$ year) prior to use. The prey, live larvae of chironomids, were obtained commercially (ZOO \& Co. Knutzen, Kiel). Gammarids were fed a mixture of ground commercial fish and shrimp flakes, supplemented with chironomid larvae in the weeks prior to experimentation. Gammarus tigrinus has previously been shown to readily consume chironomid larvae (Pellan et al. 2016).

In the controlled environment chamber, functional responses of $G$. tigrinus (total length: $0.9-1.1 \mathrm{~cm}$ ) towards live chironomid larval prey (total length: $0.6-1.1 \mathrm{~cm}$ ) were quantified factorially under two temperatures $\left(18{ }^{\circ} \mathrm{C}, 24^{\circ} \mathrm{C}\right)$, five prey densities $(2,4,8,16,32)$ and in the presence of single or double predator treatments (1 or 2 size-matched gammarid individuals). Controls consisted of prey in the absence of predators under each temperature and density treatment, to quantify non-predatory background mortality rates. At least three replicates were conducted per experimental group; all treatments were initially replicated four times, however, in some cases predator mortality or moulting during the experiment required us to exclude these replicates. Gammarids were unfed for $24 \mathrm{~h}$ prior to experimentation to standardise hunger levels in $5 \mathrm{~L}$ aquaria containing artificial stones for refuge, separate to the experimental aquaria.

Experiments were conducted in $500 \mathrm{~mL}$ plastic arenas of $12 \mathrm{~cm}$ diameter containing $10 \mathrm{ppt}$ water, within 
water baths maintained at the nominal experimental temperatures $\left(18{ }^{\circ} \mathrm{C}\right.$ or $\left.24^{\circ} \mathrm{C}\right)$. This temperature range is within the magnitude of daily fluctuations of temperature recorded in the study area (Pansch and Hiebenthal 2019), with the lower temperature reflecting ambient conditions in the Kiel Fjord (Morón Lugo et al. 2020). The higher temperature reflects changes within nearshore areas of the Baltic Sea that occur sporadically throughout the year, based on empirical data from the last two decades, owing to heatwaves which are becoming increasingly frequent (Pansch et al. 2018). Both predators and prey were acclimated separately in the $500 \mathrm{~mL}$ arenas to the higher temperature for $2 \mathrm{~h}$ at a rate of $1.5^{\circ} \mathrm{C} 30 \mathrm{~min}^{-1}$. Following acclimation, predators were added to each prey density and allowed to feed for $24 \mathrm{~h}$ (i.e. the duration of the experiment). Owing to laboratory logistics, feeding trials were run on 7 separate days, with replicates randomised within each temperature grouping per day. After this period, gammarids were removed and remaining live prey enumerated to quantify those killed via predation. Dissolved oxygen levels were monitored in both temperature treatments, and these did not fall below $80 \%$ saturation in either case. We did not observe any evidence for predation between gammarids in intraspecific multiple predator treatments.

\section{Statistics}

Median levels of prey mortality in predator-free controls at each prey density and temperature were used to account for natural prey mortality in the calculation of consumption rates in those treatments containing predators (i.e., via subtraction of control mortality from predator-driven mortality). Counts of prey killed were analysed using generalised linear models assuming a Poisson error distribution and log link, as a function of temperature, prey density and predator numbers. An information theoretic approach was used to select the model which minimised information loss via secondorder derivations of Akaike's information criterion (AICc; Burnham and Anderson 2002). A selection table was compiled with all possible combinations of explanatory terms in the model (Barton 2020), with models then ranked based on AICc, whereby lower AICc indicates a better fit. Models with $\Delta \mathrm{AICc} \leq 2$ were considered interchangeable. The final, selected model thus comprised that with the lowest AICc, with analysis of deviance with type III sums of squares then used to compute coefficients of the best fitting model (Fox and Weisberg 2019). Tukey comparisons via estimated marginal means were used for pairwise testing where a term was significant (Lenth 2020).

Gammarid functional response types (I, II or III) were categorised at the single-predator density using binomial generalised linear models with logit links for each temperature treatment separately, with consumption rates (proportion of prey killed) analysed as a function of initial prey density. Because prey were not replaced as they were killed, we fit Rogers' random predator equation (Rogers 1972; Pritchard et al. 2017) to the data to model functional response parameters (attack rate and handling time), assuming the data were properly described by a type II functional response curve (Haddaway et al. 2012; Rosenbaum and Rall 2018):

$N_{\mathrm{e}}=N_{0}\left(1-\exp \left(a\left(N_{\mathrm{e}} h-T\right)\right)\right)$,

where $N_{\mathrm{e}}$ is the number of prey eaten, $N_{0}$ is the initial density of prey, $a$ is the attack rate, $h$ is the handling time and $T$ is the total experimental period. Because $N_{\mathrm{e}}$ appears on both sides of Eq. 1, the solution was found using Lambert's transcendental equation (Bolker 2008). The difference $(\Delta)$ method was then used to compare functional response parameters ( $a$ and $h$ ) pairwise between temperatures (Pritchard et al. 2017).

To quantify the strength of non-trophic interactions in treatments with multiple gammarid predators between both temperatures, we first quantified the strength of trophic interactions that included both tropic (i.e., predatory) and non-trophic (i.e., trait-mediated) effects from experimental observations:

$\operatorname{IS}(P, Z)=\frac{N_{\mathrm{P}}-N_{\mathrm{P}, \mathrm{Z}}}{N_{\mathrm{P}}}$,

where $N_{\mathrm{P}}$ and $N_{\mathrm{P}, \mathrm{Z}}$ are the proportions of live prey at the beginning and end of the experiment, respectively. Second, using single-predator functional response parameters ( $a$ and $h$ ) quantified as per Eq. 1, we fit a population-dynamic model to simulate expected predation rates in the absence of non-trophic interactions (i.e., without intraspecific multiple predator effects) (McCoy et al. 2012; Sentis and Boukal 2018):

$\frac{\mathrm{d} N}{\mathrm{~d} t}=-\sum_{i=1}^{n} f_{i}(N) P_{i}$,

where $N$ is the prey population density, $P_{i}(i=1,2, \ldots, n)$ are the population densities of predators $i$ and $f_{i}(N)$ is the functional response of predator $i$ (i.e., Eq. 1). The equation was integrated over time to obtain expected numbers of surviving prey at each temperature treatment and prey density using a Latin hypercube sampling algorithm (Soetaert et al. 2010; Soetaert and Petzoldt 2010). Last, to quantify the strength of non-trophic interactions, the simulations from Eq. 3 (i.e., excluding non-trophic interactions) were subtracted from the observations from Eq. 2 (i.e., including non-trophic interactions) to quantify intraspecific multiple predator effects. Here, negative resulting values would indicate antagonistic predator-predator interactions given that predictions exceed observations. Conversely, synergisms would be indicated by positive values (i.e., observations exceeded 
predictions). Non-trophic interactions were analysed using a Scheirer-Ray-Hare test as a function of temperature treatment and prey density. All analyses were computed in R v4.0.2 (R Core Team 2020), with significance inferred at an $\alpha$ of 0.05 .

\section{Results}

The best fitting model of prey consumption included predator density, temperature and prey density as single and interacting terms, but excluded the three-way interaction among these variables. Intraspecific multiple predators consumed significantly more than predators present singularly (Table 1). Predator density and temperature effects, however, significantly interacted to influence prey consumption (Table 1); warming had a significant, positive effect considering single $(p=0.001)$ but not multiple $(p=0.821)$ predators. The effects of temperature were therefore different according to predator density, becoming less apparent as predator density increased. Prey density was significant in both interaction terms with predator density and temperature (Table 1). All other single terms were not statistically clear (Table 1).

Across both temperatures, G. tigrinus consumption rates related negatively with increasing prey density (Table 2 ),

Table 1 Analysis of deviance table with type III sums of squares considering Poisson generalised linear model of numbers of prey consumed as a function of predator density (Predator), temperature (Temperature) and prey density (Density)

\begin{tabular}{llll}
\hline Term & $\begin{array}{l}\text { Likelihood } \\
\text { ratio } \chi^{2}\end{array}$ & $d f$ & $p$ value \\
\hline Predator & $\mathbf{6 . 0 5 6}$ & $\mathbf{1}$ & $\mathbf{0 . 0 1 4}$ \\
Temperature & 0.049 & 1 & 0.824 \\
Density & 0.668 & 1 & 0.414 \\
Predator:Temperature & $\mathbf{5 . 6 4 4}$ & $\mathbf{1}$ & $\mathbf{0 . 0 1 8}$ \\
Predator:Density & $\mathbf{4 . 7 7 0}$ & $\mathbf{1}$ & $\mathbf{0 . 0 2 9}$ \\
Temperture:Density & $\mathbf{5 . 5 0 0}$ & $\mathbf{1}$ & $\mathbf{0 . 0 1 9}$ \\
Predator:Temperature:Density & 1.215 & 1 & 0.270 \\
\hline
\end{tabular}

Significant effects are emboldened

Table 2 First-order terms from binomial generalised linear models considering prey killed as a function of prey density across temperature and predator treatments by Gammarus tigrinus. Functional

\begin{tabular}{|c|c|c|c|c|c|}
\hline Temperature $\left({ }^{\circ} \mathrm{C}\right)$ & Predators $(n)$ & First-order term (type) & Attack rate $(a)$ & Handling time $(h)$ & $\begin{array}{l}\text { Maximum } \\
\text { feeding rate } \\
(1 / h)\end{array}$ \\
\hline 18 & 1 & $-0.105 * * *($ II $)$ & $\mathbf{5 7 . 8 8 4} * * *$ & $0.206 * * *$ & $4.854 * * *$ \\
\hline 24 & $\mathbf{1}$ & $-0.088 * * *$ (II) & $2.959 * * *$ & $0.061 * * *$ & $16.383 * * *$ \\
\hline
\end{tabular}

Asterisks denote significance levels $(*<0.05 ; * *<0.01 ; * * *<0.001)$ and significant effects are emboldened

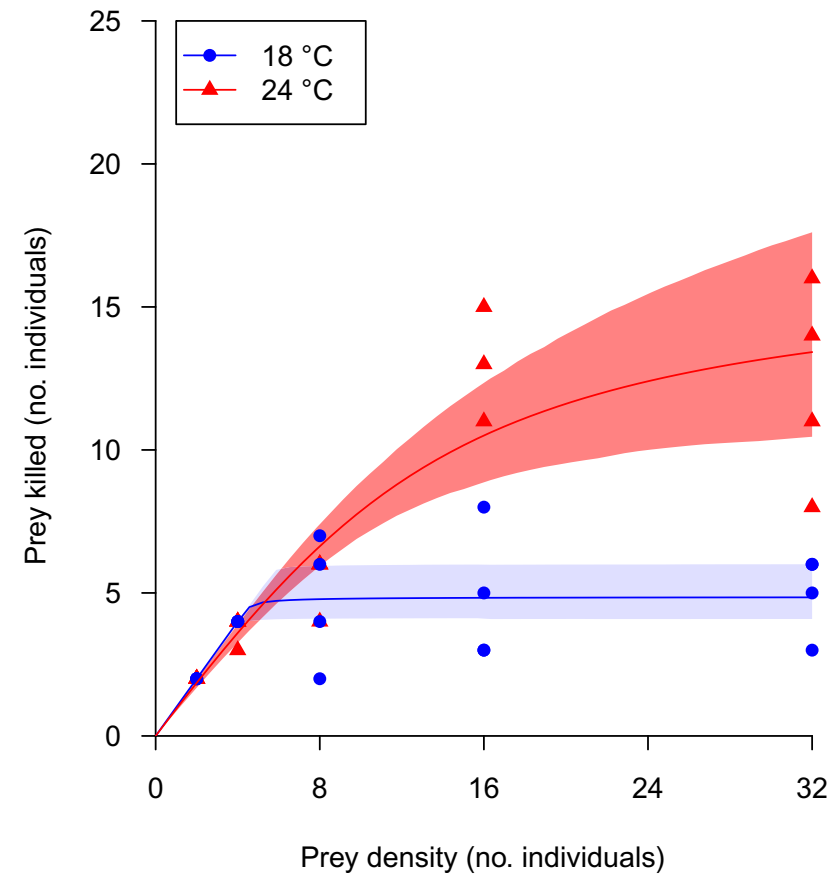

Fig. 1 Functional responses of single Gammarus tigrinus under $18{ }^{\circ} \mathrm{C}$ and $24{ }^{\circ} \mathrm{C}$ temperatures. Shaded areas are non-parametric bootstrapped $(n=2000) 95 \%$ confidence intervals. Points are raw data ited (Fig. 1). Attack rates tended to decrease with temperature, whilst handling times tended to shorten and thus maximum feeding rates increase (Table 2). Under single-predator densities, attack rates did not significantly differ between temperatures, owing to high standard error, whilst handling times were significantly shorter with warming (Table 3; Fig. 1). Accordingly, functional response initial slopes were similar between temperatures at low prey densities, yet more marked differences in magnitudes were found at high prey densities (Fig. 1).

The strength of non-trophic interactions between intraspecific multiple predators was affected by a significant interaction between temperature and prey density $(H=17.278$, $p=0.002$ ). At low prey densities ( 2 and 4 ind. arena ${ }^{-1}$ ),

response attack rates, handling times and maximum feeding rates from the random predator equation and thus hyperbolic type II functional responses were exhib- 
Table 3 Results from difference $(\Delta)$ method comparing functional response parameters of single predators between temperatures, alongside standard errors (SE)

\begin{tabular}{lrrrr}
\hline Difference $(\Delta)$ & Estimate & \multicolumn{1}{l}{ SE } & $z$ value & $p$ value \\
\hline Attack rate $(a)$ & 25.546 & 23.993 & 1.065 & 0.287 \\
Handling time $(h)$ & $\mathbf{0 . 1 4 0}$ & $\mathbf{0 . 0 2 2}$ & $\mathbf{6 . 2 6 4}$ & $<\mathbf{0 . 0 0 1}$ \\
\hline
\end{tabular}

Significant effects are emboldened

consumption rates were well-predicted from simulations, and thus no evidence for non-trophic interactions was discerned (Fig. 2). At intermediate densities ( 8 ind. arena ${ }^{-1}$ ), non-trophic interaction strengths were negative under both temperature treatments, indicating interference effects among predators. At highest prey densities (16 and 32 ind. arena $\left.^{-1}\right)$, non-trophic interactions were, in turn, dependent on temperature, with positive values (i.e., synergisms) observed at $18{ }^{\circ} \mathrm{C}$ and negative values at $24^{\circ} \mathrm{C}$ (i.e., antagonisms). Thus, the nature of intraspecific multiple predator effects was mediated by emergent interactions between temperature and prey density, with warming driving interference effects at high prey densities.

\section{Discussion}

Ecological impacts from a notorious invasive alien species in marine, brackish and freshwater habitats were shown to be mediated through intraspecific multiple predator effects between two temperatures and across a prey density gradient in the present study. Whilst warming generally intensified interaction strengths with a representative benthic prey (Pellan et al. 2016), corroborating previous studies on gammarid congenerics (Laverty et al. 2017), emergent effects that mediate invader impacts were found according to temperature and prey density. In particular, intraspecific multiple predator interactions eroded the magnitude of positive temperature effects on feeding rates. As such, despite increasing numbers of invasive gammarids heightening overall predation rates, simulations based on individual predator feeding indicated predator-predator antagonisms at higher temperatures and synergisms at low temperatures as prey densities increased. Empirically, given that functional responses are predictive of known ecological impacts (Dick et al. 2017), these results indicate that warming will worsen invader effects, but density-dependent predator-predator interacions could mitigate these impacts. Nevertheless, consistently efficient resource use by G. tigrinus at low prey densities may result in a stronger likelihood of extirpation for rare prey populations (Dick et al. 2014). Given that temperature oscillations can be of a magnitude of $21^{\circ} \mathrm{C}$ in the study area (Western Baltic Sea) between winter and summer (Pansch et al. 2018), with up to $7{ }^{\circ} \mathrm{C}$ changes reported within a single day due to day-night transitions and upwelling events (Pansch and Hiebenthal 2019), our results show invader impacts could change rapidly over short timescales in these and other coastal regions.

The strength of non-trophic interactions (i.e. multiple predator effects) was shown to differ across prey densities in the present study under both temperature regimes tested. These findings corroborate previous studies that have identified such prey density-dependencies (Sentis et al. 2017), and may be an artefact of changeable predator-predator
Fig. 2 Non-trophic interaction strengths of multiple Gammarus tigrinus across prey densities and between warming treatments. The solid horizontal line indicates expected values in the absence of non-trophic effects. Positive values indicate synergisms, and negative values antagonisms, between multiple predators

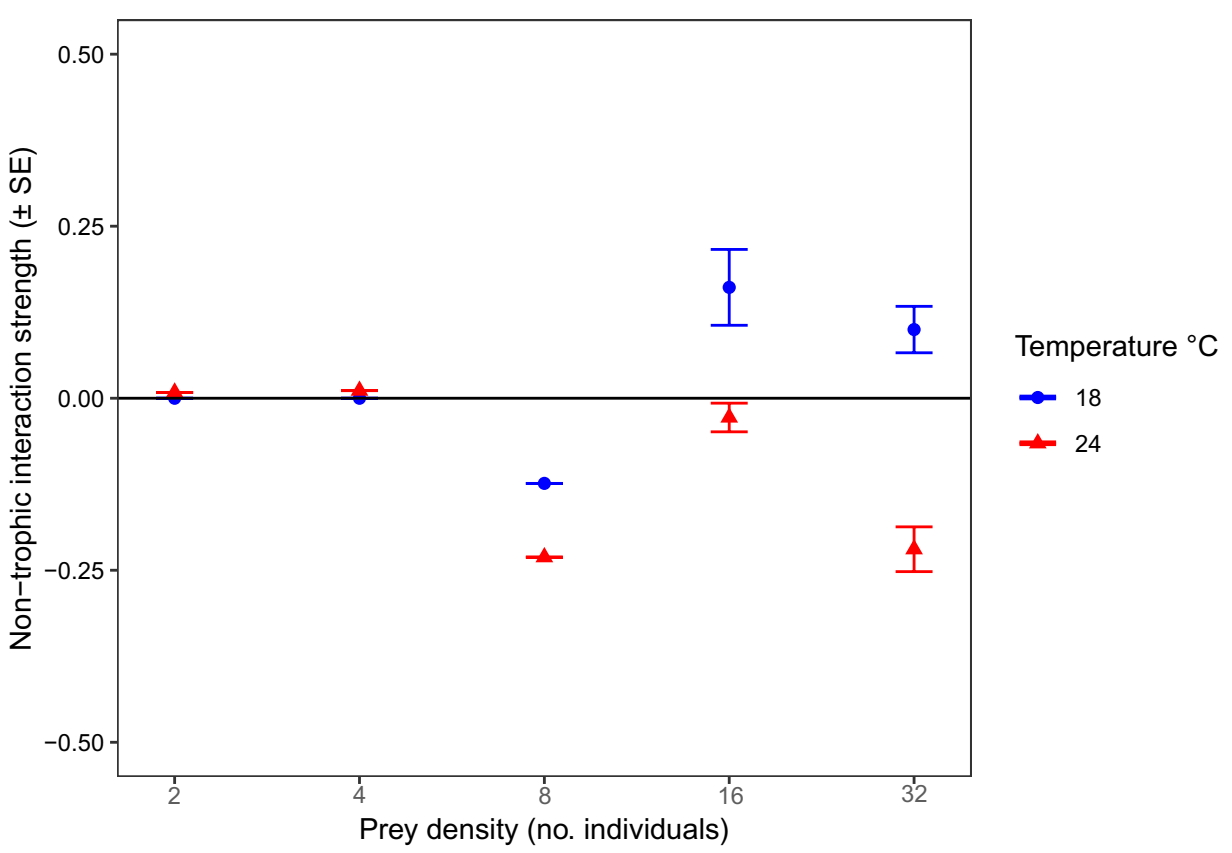


interactions as resource availability shifts. Specifically, at low prey densities, all prey are typically extirpated in nonprey replacement experimental designs, and thus there is little capacity to detect non-trophic interactions. At intermediate prey densities, competition between predators for limited resources is high, resulting in antagonisms that were detected at both temperatures in the present study. Conversely, at high prey densities, prey are abundant and thus not extirpated, with predator-predator interactions and thus multiple predator effects potentially less pertinent (Sentis et al. 2017). However, our study found temperature to additionally mediate these effects at high prey densities, whereby predators interacted positively at lower temperatures and negatively at higher temperatures. We posit that this is intertwined with predator activity rates, with foraging activity generally increasing in gammarids at higher temperatures (Laverty et al. 2017), potentially increasing predator-predator encounters and interference effects. Indeed, other notorious marine bioinvaders have similarly been shown to exhibit density-dependences in intraspecific multiple predator effects, such as lionfish (De Roy et al. 2020), yet these trends might vary according to foraging traits of individual invasive species (Wasserman et al. 2016). The effects of temperature on encounter rates thus require further investigation.

Invasions in aquatic systems by invasive alien gammarids have exhibited unidirectional patterning, with the majority of species moving from the brackish waters of the Ponto-Caspian region to Eurasian and North American freshwaters globally (Cuthbert et al. 2020). Gammarus tigrinus, however, is an exception to this phenomenon, having successfully invaded marine, brackish and freshwater ecosystems from its native range, that also spans salinities from freshwater to marine (Paiva et al. 2018). The wide-ranging salinity and temperature tolerance of this species thus heightens its invasion success, with this gammarid continuing to spread through the Baltic Sea (Rewicz et al. 2019). In turn, it is likely to impart greater impacts on prey communities in future as coastal waters warm, heatwaves intensify, and coastal regions become more interconnected globally. Whilst our results provide novel insights into the implications of warming and biotic contexts for invader ecological impacts, further work is required that incorporates additional predator densities, taxonomic groups and environmental change scenarios, as well as invader reproductive and prey responses to climate change.

Supplementary Information The online version contains supplementary material available at https://doi.org/10.1007/s00227-021-03840-z.

Acknowledgements We thank the two anonymous reviewers that provided constructive input on the manuscript.
Author contributions All authors conceptualised the study. RC performed the experiments, analysed/visualised the data and led the writing of the manuscript. All authors revised the manuscript and agreed with its submission.

Funding Open Access funding enabled and organized by Projekt DEAL. RC acknowledges funding from the Alexander von Humboldt Foundation.

Data availability Underlying data are available in the online supplementary material.

\section{Compliance with ethical standards}

Conflict of interest The submitted work was not carried out in the presence of any personal, professional, or financial relationships.

Ethical approval Ethical approval was not required for this work.

Open Access This article is licensed under a Creative Commons Attribution 4.0 International License, which permits use, sharing, adaptation, distribution and reproduction in any medium or format, as long as you give appropriate credit to the original author(s) and the source, provide a link to the Creative Commons licence, and indicate if changes were made. The images or other third party material in this article are included in the article's Creative Commons licence, unless indicated otherwise in a credit line to the material. If material is not included in the article's Creative Commons licence and your intended use is not permitted by statutory regulation or exceeds the permitted use, you will need to obtain permission directly from the copyright holder. To view a copy of this licence, visit http://creativecommons.org/licenses/by/4.0/.

\section{References}

Anton A, Geraldi NR, Ricciardi A, Dick JTA (2020) Global determinants of prey naiveté to exotic predators. Proc Roy Soc B 287:20192978

Barton K (2020) MuMIn. Multi-model inference. R package version 1.43 .17

Bolker BM (2008) Ecological models and data in R. Princeton University Press, Princeton

Boyd PW, Collins S, Dupont S, Fabricius K, Gattuso J-P, Havenhand J, Hutchins DA, Riebesell U, Rintoul MS, Vichi M, Biswas H, Ciotti A, Gao K, Gehlen M, Hurd CL, Kurihara H, McGraw CM, Navarro J, Nilsson GE, Passow U, Pörtner H-O (2018) Experimental strategies to assess the biological ramifications of multiple drivers of global ocean change- a review. Glob Change Biol 24:2239-2261

Burnham KP, Anderson DR (2002) Model selection and multi-model inference: a practical information-theoretic approach. Springer, New York

Casties I, Seebens H, Briski E (2016) Importance of geographic origin for invasion success: a case study of the North and Baltic Seas versus the Great Lakes-St. Lawrence River region. Ecol Evol 6:8318-8329

Cuthbert RN, Kotronaki S, Dick JTA, Briski E (2020) Salinity tolerance and geographic origin predict global alien amphipod invasions. Biol Lett 16:20200354 
De Roy E, Scott R, Hussey NE, MacIsaac HJ (2020) Density dependence mediates the ecological impact of an invasive fish. Divers Distrib 26:867-880

Dick JTA, Alexander ME, Jeschke JM, Ricciardi A, MacIsaac HJ, Robinson TB, Kumschick S, Weyl OLF, Dunn AM, Hatcher MJ, Paterson RA, Farnsworth KD, Richardson DM (2014) Advancing impact prediction and hypothesis testing in invasion ecology using a comparative functional response approach. Biol Invasions 15:837-846

Dick JTA, Laverty C, Lennon JJ, Barrios-O’Neill D, Mensink PJ, Britton JR, Medoc V, Boets P, Alexander ME, Taylor NG, Dunn AM, Hatcher MJ, Rosewarne PJ, Crookes S, MacIsaac HJ, Xu M, Ricciardi A, Wasserman RJ, Ellender BR, Weyl OLF, Lucy FE, Banks PB, Dodd JA, MacNeil C, Penk MR, Aldridge DC, Caffrey JM (2017) Invader Relative Impact Potential: a new metric to understand and predict the ecological impacts of existing, emerging and future invasive alien species. J Appl Ecol 54:1259-1267

Dickey JWE, Cuthbert RN, South J, Britton JR, Caffrey J, Chang X, Crane K, Coughlan NE, Fadaei E, Farnsworth KD, Ismar-Rebitz SMH, Joyce PWS, Julius M, Laverty C, Lucy FE, MacIsaac HJ, McCard M, McGlade CLO, Reid N, Ricciardi A, Wasserman RJ, Weyl OLF, Dick JTA (2020) On the RIP: using relative impact potential to assess the ecological impacts of invasive alien species. NeoBiota 55:27-60

Didham RK, Tylianakis JM, Hutchison MA, Ewers RM, Gemmell NJ (2005) Are invasive species the drivers of ecological change? Trends Ecol Evol 20:470-474

Englund G, Ohlund G, Hein CL, Diehl S (2011) Temperature dependence of the functional response. Ecol Lett 14:914-921

Fox J, Weisberg S (2019) An R companion to applied regression. Sage, Thousand Oaks

Haddaway NR, Wilcox RH, Heptonstall RE, Griffiths HM, Mortimer RJ, Christmas M, Dunn AM (2012) Predatory functional response and prey choice identify predation differences between native/invasive and parasitised/unparasitised crayfish. PLoS ONE 7:e32229

Hassell MP (1978) Functional responses. In: Hassell M (ed) The dynamics of arthro-pod predator-prey systems. Princeton University Press, Princeton, pp 28-49

Holling CS (1959) Some characteristics of simple types of predation and parasitism. Can Entomol 91:385-398

Laverty C, Brenner D, McIlwaine C, Lennon JJ, Dick JTA, Lucy FE, Christian KA (2017) Temperature rise and parasitic infection interact to increase the impact of an invasive species. Int J Parasitol 47:291-296

Lenth R (2020) emmeans: estimated marginal means, aka least-squares means. $\mathrm{R}$ package version 1.4 .8

McCoy MW, Stier AC, Osenberg CW (2012) Emergent effects of multiple predators on prey survival: the importance of depletion and the functional response. Ecol Lett 15:1449-1456

Médoc V, Spatato T, Arditi V (2013) Prey: predator ratio dependence in the functional response of a freshwater amphipod. Freshw Biol 58:858-865

Morón Lugo S, Baumeister M, Nour OM, Wolf F, Stump M, Pansch C (2020) Warming and temperature variability determine the performance of two invertebrate predators. Sci Rep 10:6780

Ojaveer H, Jaanus A, MacKenzie BR, Martin G, Olenin S, Radziejewska T, Telesh I, Zettler ML, Zaiko A (2010) Status of biodiversity in the Baltic Sea. Pub Lib Sci One 5:e12367

Paiva F, Barco A, Chen Y, Mirzajani A, Chan FT, Lauringson V, Baltazar-Soares M, Zhan A, Bailey SA, Javidpour J, Briski E (2018) Is salinity an obstacle for biological invasions? Glob Change Biol 24:2708-2720

Pansch C, Hiebenthal C (2019) A new mesocosm system to study the effects of environmental variability on marine species and communities. L\&O Methods 17:145-162

Pansch C, Scotti M, Barbozza F, Al-Janabi B, Briski E, Paiva F, Saha M, Sawall Y, Weinberger F, Yto M, Wahl M (2018) Heat waves and their significance for a temperate benthic community: a nearnatural experimental approach. Glob Change Biol 24:4357-4367

Pellan L, Médoc V, Renault D, Spataro T, Piscart C (2016) Feeding choice and predation pressure of two invasive gammarids, Gammarus tigrinus and Dikerogammarus villosus, under increasing temperature. Hydrobiologia 781:43-54

Platvoet D, Dick JTA, MacNeil C, Van Riel MC, Van der Velde G (2009) Invader-invader interactions in relation to environmental heterogeneity leads to zonation of two invasive amphipods, Dikerogammarus villosus (Sowinsky) and Gammarus tigrinus Sexton: amphipod pilot species project (AMPIS) report 6. Biol Invasions 11:2085-2093

Pritchard DW, Paterson RA, Bovy HC, Barrios-O'Neill D (2017) FRAIR: an R package for fitting and comparing consumer functional responses. Methods Ecol Evol 8:1528-1534

Pyšek P, Hulme PE, Simberloff D, Bacher S, Blackburn TM, Carlton JT, Dawson W, Essl F, Foxcroft LC, Genovesi P, Jeschke JM, Kühn I, Liebhold AM, Mandrak NE, Meyerson LA, Pauchard A, Pergl J, Roy HE, Seebens H, van Kleunen M, Vilà M, Wingfield MJ, Richardson DM (2020) Scientists' warning on invasive alien species. Biol Rev 95:1511-1534. https://doi.org/10.1111/ brv. 12627

R Core Team (2020) R: A language and environment for statistical computing. $\mathrm{R}$ foundation for statistical computing, Vienna

Rewicz T, Grabowski M, Tończyk G, Konopacka A, Bącela-Spychalska K (2019) Gammarus tigrinus Sexton, 1939 continues its invasion in the Baltic Sea: first record from Bornholm (Denmark). Bioinvasions Rec 8:862-870

Ricciardi A, Hoopes MF, Marchetti MP, Lockwood JL (2013) Progress towards understanding the ecological impacts of non- native species. Ecol Monogr 88:263-282

Rogers D (1972) Random search and insect population models. J Anim Ecol 42:369-383

Rosenbaum B, Rall BC (2018) Fitting functional responses: direct parameter estimation by simulating differential equations. Methods Ecol Evol 9:2076-2090

Sentis A, Boukal DS (2018) On the use of functional responses to quantify emergent multiple predator effects. Sci Rep 8:11787

Sentis A, Gémard C, Jaugeon G, Boukal DS (2017) Predator diversity and environmental change modify the strengths of trophic and nontrophic interactions. Glob Change Biol 23:2629-2640

Sih A, Englund G, Wooster D (1998) Emergent impacts of multiple predators on prey. Trends Ecol Evol 13:350-355

Simberloff D, Martin J-L, Genovesi P, Maris V, Wardle DA, Aronson J, Courchamp F, Galil B, García-Berthou E, Pascal M, Pyšek P, Sousa R, Tabacchi E, Vilà M (2013) Impacts of biological invasions: what's what and the way forward. Trends Ecol Evol 28:58-66

Soetaert K, Petzoldt T (2010) Inverse modelling, sensitivity and Monte Carlo analysis in R using package FME. J Stat Softw 33:1-28

Soetaert K, Petzoldt T, Setzer RW (2010) Solving differential equations in R Package deSolve. J Stat Softw 33:1-25

Vilà M, Espinar JL, Hejda M, Hulme PE, Jarošík V, Maron JL, Pergl J, Schaffner U, Sun Y, Pyšek P (2011) Ecological impacts of invasive alien plants: a meta-analysis of their effects on species, communities and ecosystems. Ecol Lett 14:702-708

Wasserman RJ, Alexander ME, Dalu T, Ellender BR, Kaiser H, Weyl OLF (2016) Using functional responses to quantify interaction effects among predators. Funct Ecol 30:1988-1998

Wasserman RJ, Cuthbert RN, Dalu T, Alexander ME (2018) Shifting interaction strength between estuarine mysid species across a temperature gradient. Mar Environ Res 140:390-393

Publisher's Note Springer Nature remains neutral with regard to jurisdictional claims in published maps and institutional affiliations. 